artículos derivados de proyectos de investigación 



\section{Medición de activos no financieros. Un análisis de los elementos que intervienen en la decisión de la gerencia al optar por el modelo del valor razonable*}

doi: 10.11144/Javeriana.cc16-40.manf

\section{Heiberg Andrés Castellanos-Sánchez}

Profesor asistente, Departamento de Contabilidad y

Finanzas, Universidad de los Andes, ULA, Mérida,

Venezuela. Jefe de la cátedra de contabilidad superior, ULA. Integrante del Grupo de Investigación en Finanzas, Auditoría, Contabilidad y Epistemología, GIFACE, del posgrado en ciencias contables, ULA. Participante de la sexta cohorte del doctorado en ciencias contables, ULA. Magíster en ciencias contables, licenciado en contaduría pública, licenciado en administración, egresado, ULA. Contacto: heiberg@ula.ve

\footnotetext{
* Este artículo de reflexión derivado de la tesis doctoral Indicadores de conservadurismo difusos en estados financieros bajo NIIF, desde la teoría positiva de la contabilidad de Watts y Zimmerman, dentro del doctorado en ciencias contables, Universidad de los Andes, ULA, Venezuela. El objetivo general del proyecto de tesis doctoral es construir indicadores de conservadurismo difusos en el marco de un conjunto completo de estados financieros bajo NIIF, desde la teoría positiva de Watts y Zimmerman. La fecha estimada de terminación de la tesis doctoral es diciembre de 2016. Investigación Libre II, asignatura adscrita al doctorado en ciencias contables, Universidad de los Andes, ULA, Mérida, Venezuela.
} 
Resumen Las Normas Internacionales de Información Financiera (2014) prevén un tratamiento alternativo para la medición posterior de activos no financieros. A tal efecto, al momento de definir sus políticas contables, la gerencia de la entidad debe seleccionar entre el modelo del costo histórico y el modelo del valor razonable. Este trabajo investigativo se centra en examinar los elementos que intervienen en la decisión de la gerencia al optar por la aplicación del valor razonable en la medición de activos no financieros. El estudio se enmarca en un enfoque cualitativo, circunscrito a la modalidad documental. En esta revisión, destaca la identificación de elementos relacionados con relevancia de la información financiera, restricción del costo, medidas de rentabilidad, medidas de endeudamiento, medidas de costo de oportunidad y perfil de la gestión empresarial.

Palabras clave Valor razonable; medición; activos no financieros; Normas Internacionales de Información Financiera.

\section{Código JEL M41}

\section{Measurement of Nonfinancial Assets.} An Analysis of the Elements Involved in the Management Decision Regarding Choosing the Reasonable Cost Model

\footnotetext{
Abstract The International Financial Reporting Standards (2014) foresee an alternative treatment for the posterior measurement of nonfinancial assets. For this purpose, when defining its accounting policies, the management of the company must choose between the historical cost model and the reasonable cost model. This research work focuses on examining the elements involved in the decision of the management regarding choosing the application of reasonable cost in the measurement of nonfinancial assets. The study is framed by a qualitative approach, within the documentary modality. In this review we highlight the identification of elements related with the relevance of the financial information, restrictions of the cost, profitability
}

measures, indebtedness measures, opportunity cost measures, and profile of the company management.

Keywords Reasonable cost; nonfinancial assets; International Financial Reporting Standards

\section{Mensuração de ativos não financeiros. Análise dos elementos que intervém na decisão da gerencia de optar pelo modelo de valor justo razoável}

Resumo As Normas Internacionais de Informação Financeira (2014) fornecem um tratamento alternativo para a mensuração subsequente de ativos não financeiros. Para tal efeito, no momento de definir as políticas contábeis, a gerencia da entidade deve selecionar entre o modelo de custo histórico e o modelo de valor justo razoável. Este trabalho de pesquisa centra-se em examinar os elementos que intervêm na decisão da gerencia de optar pela aplicação do valor razoável na mensuração de ativos não financeiros. O estudo baseia-se num enfoque qualitativo, circunscrito na modalidade documental. Nesta revisão salienta a identificação de elementos relacionados com a relevância da informação financeira, restrição do custo, medidas de rendibilidade, medidas de endividamento, medidas de custo de oportunidade e perfil da gestão empresarial.

Palavras-chave Valor justo razoável; mensuração; ativos não financeiros; Normas Internacionais de Informação Financeira

\section{Preliminares}

La expansión acelerada del proceso de armonización contable internacional ha generado un escenario favorable para que un importante número de naciones, alrededor del mundo, adopten en forma total o parcial estándares contables de aceptación general. Esta crecien- 
te tendencia ha tenido como propósito que las organizaciones, independientemente de la jurisdicción donde ejecuten sus operaciones, preparen su información financiera a partir de criterios universales y unificados de reconocimiento, valoración y presentación.

Actualmente, las Normas Internacionales de Información Financiera (NIIF) (2014), emitidas por el Consejo de Normas Internacionales de Contabilidad (IASB ${ }^{1}$ ) se han consolidado como el marco normativo de mayor repercusión en el ámbito contable ${ }^{2}$. Al respecto, Hernán Casinelli (2008, p. 28) expresa que "la globalización de los negocios y las finanzas han permitido que más de doce mil (12.000) compañías en más de cien (100) países hayan adoptado las NIIF para elaborar sus estados financieros".

En el marco regulatorio del IASB (2014), entre otras acepciones valorativas, prevalece el constructo contable del valor razonable, utilizado de forma obligatoria u optativa para la valoración inicial y/o posterior de importantes grupos de activos y pasivos.

El valor razonable es conceptualizado en la NIIF 13 Medición del valor razonable (2014) específicamente, en su párrafo 24, como:

El precio que se recibiría por la venta de un activo o se pagaría por la transferencia de un pasivo en una transacción ordenada en el mercado principal (o más ventajoso) en la fecha de la medición en condiciones de mer-

1 En adelante, IASB por sus siglas en inglés: International Accounting Standards Board.

2 En la actualidad, 101 jurisdicciones en el globo han adoptado las NIIF como sus estándares contables de aceptación general. Información tomada del sitio web del IASB. cado presentes (es decir, un precio de salida) independientemente de si ese precio es observable directamente o estimado utilizando otra técnica de valoración (p. 8).

Conviene puntualizar que un modelo contable fundamentado en el criterio valorativo del valor razonable introduce cambios sustanciales a las prácticas convencionales ${ }^{3}$ de reconocimiento, medición, presentación y revelación de la información financiera.

En cuanto al reconocimiento, es posible entrever aspectos de interés vinculados a la incorporación de elementos contables que surgen por la variación del valor razonable de partidas específicas, entre la fecha de adquisición o contratación y la fecha en la que se informa. Algunas partidas que ilustran la aserción anterior son los cambios en el valor razonable de un elemento (partida contable reconocida en resultados, representada por ingresos o gastos operacionales), los cambios integrales en el valor razonable de un elemento (cuenta de otros resultados integrales, referida a ganancias o pérdidas de otros resultados integrales), el superávit en revaluación de activos (cuenta de patrimonio, relacionada con la revaluación de activos no financieros) y los costos financieros (cuenta de resultados, concerniente a financiamientos implícitos), entre otras.

3 Tradicionalmente, el proceso de obtención de las cifras contables ha estado supeditado al criterio valorativo del costo histórico. Incluso, el Marco conceptual para la información financiera (2014) en su párrafo 4.56 indica que "la base o método de medición más comúnmente utilizado por las entidades, al preparar sus estados financieros, es el costo histórico". 
En relación con la medición, los principales cambios están orientados a la introducción de distintos niveles de variables ${ }^{4}$ para la obtención del valor razonable de un elemento. Estas variables abarcan desde precios cotizados ( $\mathrm{sin}$ ajustar) de activos o pasivos idénticos o similares a los que la entidad controla, hasta técnicas financieras con altos grados de complejidad. A continuación, se mencionan algunas herramientas financieras (variables o datos de entrada de tercer nivel) que simbolizan la distancia entre la práctica de valoración tradicional y el modelo del valor razonable; estas son el valor presente esperado, el ajuste a la tasa de descuento, la matriz de precios, el costo promedio ponderado de capital, el modelo de valuación de activos de capital y las curvas de rendimiento, entre otras.

Aunado a ello, los aspectos claves relativos a presentación que son susceptibles a cambios se encaminan a hacer visible, en el conjunto completo de estados financieros, las nuevas partidas o grupos de partidas que se reconocen al momento de aplicar el valor razonable. Seguidamente, se citan algunos ejemplos alusivos a la incidencia de la acepción de valor razonable en la presentación.

En primer término, el Estado del resultado del período y otro resultado integral debe mostrar las ganancias o pérdidas por los cambios en el valor razonable de una partida (reconocidas directamente en resultados, como las variaciones del importe de las propiedades de inver-

4 Para un mayor grado de detalle, consultar los párrafos del 72 al 90 de la NIIF 13 (2014). sión ${ }^{5}$ ), y las ganancias o pérdidas integrales por cambios en el valor razonable de una partida (reconocidas directamente en otros resultados integrales, siendo el caso de la fluctuación de valor de las propiedades, planta y equipo ${ }^{6}$ ).

En segundo término, el Estado de Situación Financiera o Balance General exhibirá las partidas medidas a valor razonable relativas con activos y pasivos que se afectaron por el reconocimiento de las ganancias y pérdidas por los cambios en sus valores razonables. De ser necesario, para su óptima comprensión se presentarán por separado las partidas de activos y pasivos, en el mismo cuerpo del estado financiero, del resto de partidas medidas en atención a otras acepciones contables. Con ocasión de la valoración de activos a valor razonable, pueden surgir partidas de patrimonio, específicamente de superávit, que estarán sujetas a presentación. Tal es el caso del superávit por revaluación ${ }^{7}$, inmerso en la medición, por ejemplo, de propiedades, planta y equipo.

En tercer término, en el renglón de ajustes al resultado, el Estado de Flujos de Efectivo debe excluir cualquier partida que represente un ingreso o egreso operacional por concepto de variaciones en el valor razonable, en virtud de que estas cuentas no afectan el movimiento del efectivo de un período determinado.

En cuarto término, en caso de aplicar, el Estado de Cambios en el Patrimonio debe agregar a su presentación tradicional las partidas con-

\footnotetext{
5 Ver párrafo 35 de la NIC 40 (2014) "Propiedades de Inversión".

6 Ver párrafo 39 de la NIC 16 (2014) "Propiedades, Planta y Equipo".

7 Ver párrafo 39 de la NIC 16 (2014) "Propiedades, Planta y Equipo".
} 
cernientes a ganancias o pérdidas integrales por cambios en el valor razonable de una partida específica, así como los aumentos y disminuciones en esa cuenta. Del mismo modo, agregará la partida de superávit por revaluación.

En quinto término, las Notas Explicativas ${ }^{8}$ deben revelar la fuente de obtención del importe razonable, con un importante nivel de detalle. En otras palabras, se requiere pormenorizar sobre el proceso de medición: si el valor se calculó a partir de cotizaciones disponibles en el mercado, si fue necesario un ajuste a esos precios cotizados, o si el importe razonable se alcanzó con técnicas financieras.

Como se puede apreciar, la medición de elementos contables a valor razonable implica la incorporación de notables cambios a la práctica de la contabilidad. No obstante, medir un activo o pasivo aplicando el criterio valorativo de valor razonable es, exclusivamente, una decisión facultativa de la gerencia de la entidad, en virtud de la permisividad descrita en el marco normativo

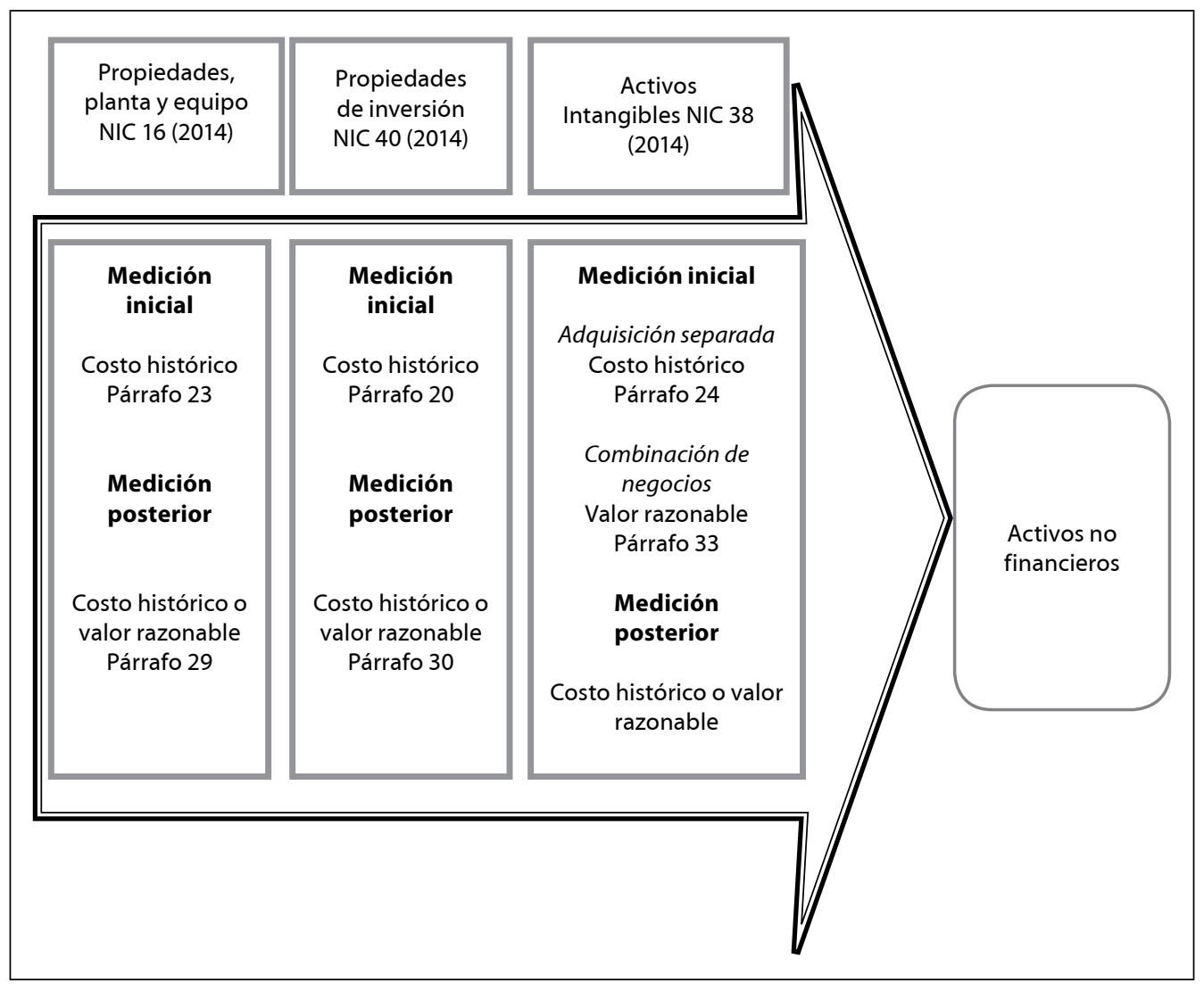

Gráfico 1. Criterios de medición de activos no financieros en las NIIF (2014)

Fuente: elaboración propia

8 Para profundizar, puede consultar los párrafos del 91 al

99 de la NIIF 13 (2014). 
del IASB (2014). Esta afirmación se ilustra en el gráfico 1, al caracterizar la dualidad de criterios de valoración que se encuentran presentes en las NIIF (2014) para activos no financieros, específicamente se describe el tratamiento contable de propiedades, planta y equipo, propiedades de inversión y activos intangibles.

En este contexto, la presente investigación se propone como objetivo general analizar los elementos que intervienen en la decisión de la gerencia para medir a valor razonable los activos no financieros ${ }^{9}$, a la luz de las Normas Internacionales de Información Financiera (2014). Conviene puntualizar que este documento es el primer producto de una revisión bibliográfica realizada sobre la medición a valor razonable de activos no financieros.

\section{Trabajos recientes relacionados con la medición de activos no financieros}

En este apartado se seleccionaron dos investigaciones recientes que tratan de identificar los elementos que son considerados por la gerencia al momento de medir un activo no financiero. Otro aspecto relevante es que ambos trabajos son desarrollados en un ambiente NIIF.

\subsection{El trabajo de Christensen \& Nikolaev} (2013)

La investigación de Hans Bonde Christensen \& Valeri V. Nikolaev (2013) se abocó al estudio del tratamiento de medición de los activos no financieros relacionados con propiedades, plan-

\begin{tabular}{|c|c|c|c|c|}
\hline \multirow[b]{2}{*}{ Tipo de activo } & \multicolumn{2}{|c|}{ PCGA de Alemania } & \multicolumn{2}{|c|}{ PCGA del Reino Unido } \\
\hline & $\begin{array}{l}\text { Estado de } \\
\text { situación } \\
\text { financiera }\end{array}$ & $\begin{array}{l}\text { Estado de } \\
\text { resultados }\end{array}$ & $\begin{array}{l}\text { Estado de } \\
\text { situación } \\
\text { financiera }\end{array}$ & $\begin{array}{l}\text { Estado de } \\
\text { resultados }\end{array}$ \\
\hline $\begin{array}{l}\text { Propiedades, planta } \\
\text { y equipo }\end{array}$ & Costo histórico & $\begin{array}{l}\text { Depreciaciones, } \\
\text { deterioros, ganancias y } \\
\text { pérdidas realizadas }\end{array}$ & $\begin{array}{l}\text { Valor razonable, VR o } \\
\text { costo histórico, } \mathrm{CH}\end{array}$ & $\begin{array}{l}\text { Tanto CH como } \\
\text { VR: depreciaciones, } \\
\text { deterioros, ganancias y } \\
\text { pérdidas realizadas }\end{array}$ \\
\hline $\begin{array}{l}\text { Propiedades de } \\
\text { inversión }\end{array}$ & Costo histórico & $\begin{array}{l}\text { Depreciaciones, } \\
\text { deterioros, ganancias y } \\
\text { pérdidas realizadas }\end{array}$ & Valor razonable & $\begin{array}{l}\text { Depreciaciones, } \\
\text { deterioros, ganancias y } \\
\text { pérdidas realizadas }\end{array}$ \\
\hline Activos intangibles & Costo histórico & $\begin{array}{l}\text { Depreciaciones, } \\
\text { deterioros, ganancias y } \\
\text { pérdidas realizadas }\end{array}$ & $\begin{array}{l}\text { Costo histórico o valor } \\
\text { razonable (si existe un } \\
\text { mercado activo) }\end{array}$ & $\begin{array}{l}\text { Tanto CH como } \\
\text { VR: depreciaciones, } \\
\text { deterioros, ganancias y } \\
\text { pérdidas realizadas }\end{array}$ \\
\hline
\end{tabular}

Tabla 1. Tratamiento contable de activos no financieros bajo PCGA de Alemania y PCG del Reino Unido Fuente: tomado de Hans Bonde Christensen y Valeri V. Nikolaev (2013)

9 El alcance de la investigación se circunscribe a Propiedades de Inversión y Propiedades, Planta y Equipos. ta y equipo, propiedades de inversión y activos intangibles. Los autores calificaron este grupo de activos como uno de los más polémicos en el ámbito valorativo. 
Concretamente, los académicos confrontaron los estados financieros de entidades del Reino Unido con entidades de Alemania, en virtud de que ambos países simbolizaban los extremos en las prácticas contables relativas a los activos no financieros. Con anterioridad a la adopción de las NIIF en la Unión Europea $^{10}$, los principios de contabilidad de aceptación general (PCGA) en el Reino Unido exigían la medición de propiedades, planta y equipo y propiedades de inversión al valor razonable, mientras los estándares contables de Alemania se limitaban a la medición de esta categoría de activos a la pauta del costo histórico. La tabla 1 muestra las diferencias en materia de medición que ostentaban los PCGA alemanes y los PCGA del Reino Unido. Al margen de las normas locales de las jurisdicciones del Reino Unido y Alemania, las NIIF convergen en un tratamiento alternativo entre el costo histórico y el valor razonable para los activos no financieros.

Los estados financieros de las entidades del Reino Unido y Alemania fueron extraídos de la base de datos Worldscope ${ }^{11}$. Para este estudio se examinó la sección de políticas contables de las notas a los estados financieros, concernientes a

10 La Unión Europea decidió adoptar las NIIF a partir del 1 de enero de 2005.

11 La base de datos Worldscope presenta información financiera sobre las principales entidades públicas y privadas alrededor del mundo. Adicional a los estados financieros, Worldscope ofrece la siguiente información financiera: datos financieros normalizados, datos dinámicos, descripciones detalladas de negocios, datos de ventas por segmentos geográficos, información intermedia de entidades, información multiacción, tasas de crecimiento, tipos de cambio, dividendos, relación precio-beneficio, rentabilidad, beneficio por acción, valor de mercado, volumen de valores negociados y de acciones en circulación. la medición de activos no financieros, en 1.539 entidades, cifra que hace referencia al universo de empresas alemanas e inglesas inscritas en la mencionada base de datos.

La premisa central de la investigación revela que las decisiones de la gerencia, al valorar activos no financieros, atienden a la influencia de las fuerzas de mercado. En otras palabras, quienes determinan qué criterio valorativo emplear son los participantes en el mercado (usuarios interesados en la información financiera).

Para conducir con éxito su trabajo investigativo, los autores se valieron de un análisis costo-beneficio, enmarcado en la restricción del costo en la información financiera útil dispuesta en el Marco conceptual para la información financiera (2014). Según los investigadores, el beneficio de aplicar el valor razonable en reemplazo del costo histórico se relaciona con una supremacía, casi absoluta, en la mayoría de las características cualitativas de la información financiera presentes en el cuerpo normativo del IASB (2014). Para los académicos, el gran inconveniente que enfrenta el valor razonable es la característica cualitativa de fiabilidad ${ }^{12}$, territorio dominado por el costo histórico objetivo. Mientras el costo asociado a la obtención de valores razonables confiables constituye un factor clave en la elección del método a emplear.

Por otra parte, las predicciones empíricas o hipótesis del estudio de Hans Bonde Christenseny Valeri V. Nikolaev (2013) estaban encaminadas a obtener evidencia, basada en el mercado, sobre los tratamientos contables de

12 En el Marco conceptual para la información financiera (2014) no se utiliza el término fiabilidad; en contraste, se enuncia el término representación fiel. 
medición aplicables a activos no financieros. Los autores enfatizaron que, en la literatura contable, este tipo de evidencia era muy limitada.

La hipótesis 1 buscaba comprobar que, luego de la adopción de las NIIF en la Unión Europea, las entidades de Alemania eran menos propensas a utilizar el valor razonable que las entidades del Reino Unido, debido a que la práctica contable tradicional de las empresas alemanas estaba supeditada a la acepción del costo histórico. En este contexto, la hipótesis 1 era la siguiente " $\mathrm{H} 1$ : el valor razonable es más probable que se utilice en el Reino Unido que en Alemania después de la adopción de las NIIF"13" (Christensen \& Nikolaev, 2013, p. 742).

La hipótesis 2 pretendió demostrar la relación existente entre la decisión de la gerencia de medir a valor razonable un activo no financiero y el esfuerzo y recursos que una entidad debe destinar para obtener un valor razonable que genere confianza al usuario de la información. Los autores destacaron que la capacidad de una entidad de obtener importes razonables está estrechamente relacionada con la existencia de mercados líquidos, en virtud de que proporcionan una fuente independiente de verificación. Para el caso de activos no financieros, las propiedades inmobiliarias tienen asociados mercados relativamente más líquidos que otros activos de estas categorías. Por tanto, la hipótesis 2 indicó: "H2: los gerentes son más propensos a elegir la contabilidad del valor razonable de propiedades, planta y equipo y propiedades de inversión ${ }^{14 "}$ (Christensen \& Nikolaev, 2013, p. 742).

La hipótesis 3 procuraba evidenciar que la aplicación del criterio valorativo del valor razonable era, probablemente, más útil para evaluar la gestión de una entidad. Ciertamente, al emplear el valor razonable, la medición del desempeño de los gerentes se ve afectada, cuando se relacionan los importes de los activos con el rendimiento empresarial. En este sentido, la hipótesis 3 revela "H3: el valor razonable es más probable que se utilice cuando el reconocimiento de cambios de valor de los activos en forma oportuna facilita la medición del desempeño ${ }^{15 "}$ (Christensen \& Nikolaev, 2013, p. 743).

La hipótesis 4 intentó probar la existencia de una relación entre el uso de la contabilidad a valor razonable y la necesidad de acceder a un mercado de deuda o financiación. Las empresas que obtienen financiamiento deben proporcionar a sus acreedores y prestamistas información financiera que asegure o dé garantía de su capacidad de pago. Los investigadores al enunciar que la aplicación de la acepción de valor razonable representa mayores beneficios, en términos de la calidad de la información reportada, infieren que la contabilidad a valor razonable coadyuvará a generar más confianza en los acreedores. En conexión, la hipótesis 4 puntualizó: "H4: la contabilidad a valor razonable tiene una asociación con la dependencia de la deuda financiera ${ }^{16 "}$ " (Christensen \& Nikolaev, 2013, p. 743).

14 Traducción libre del inglés al castellano.

15 Traducción libre del inglés al castellano.

16 Traducción libre del inglés al castellano. 
Los resultados obtenidos por Christensen \& Nikolaev (2013) revelaron, en atención a la primera hipótesis, que efectivamente las entidades del Reino Unido, luego de la adopción de las NIIF, utilizan con mayor frecuencia el valor razonable como criterio de medición de sus activos no financieros. A pesar de ello, se constató que el 44\% de las entidades del Reino Unido aplicó el costo histórico, una vez que la obligatoriedad del valor razonable pasó a un plano opcional o facultativo con apego a las NIIF. En contraste, se detectó que solo el 1\% de las entidades de Alemania optó por medir sus activos no financieros a valor razonable, al momento de estar disponible esta acepción valorativa.

Las instituciones reguladoras de cada jurisdicción, con su práctica contable tradicional, incidieron en la decisión de valoración que tomó la gerencia de las entidades en el momento de la transición hacia las NIIF. Los académicos concluyen que la gerencia de las entidades no consideró beneficiosa la aplicación del valor razonable, al no existir una extensiva migración hacia este criterio de valoración.

Por su parte, la hipótesis 2 fue aceptada. Los gerentes de las entidades utilizan, con mayor frecuencia, el valor razonable para medir propiedades, planta y equipo y propiedades de inversión, ya que los mercados inmobiliarios son más líquidos que los mercados de otros activos no financieros. En otras palabras, los costos de obtener importes razonables en mercados líquidos son relativamente más bajos.

Este estudio evidenció que para propiedades, plantas y equipos solo el 3\% de las empresas de la muestra empleó el valor razonable para valorar al menos una clase de este grupo de activos, siendo su mayor uso en propiedades, ya que las plantas y los equipos se valoraron, casi en su totalidad, a costo histórico. En el caso de las propiedades de inversión, no se comprobó que la gerencia favoreciera una medida en particular, puesto que había la misma probabilidad de utilizar el valor razonable y el costo histórico. En cuanto a los activos intangibles, los resultados dejaron ver que todas las empresas de la muestra emplearon como política contable el costo histórico.

De igual forma, la hipótesis 3 fue admitida. Los autores detectaron que la gerencia utiliza, en mayor medida, el valor razonable cuando presume que este importe facilitará la medición del desempeño. Por ejemplo, las entidades dedicadas a bienes raíces como actividad empresarial primaria, mostraron una marcada predilección por el uso del valor razonable, lo cual resulta lógico debido a que las ganancias de capital son parte del modelo de negocio, y el valor razonable contribuye al suministro de información sobre la gestión de sus bienes. Asimismo, el estudio encontró, en menor proporción, entidades caracterizadas por contar con pocas oportunidades de inversión, que emplearon el valor razonable como mecanismo de control sobre las políticas de inversión en activos improductivos.

En este orden de ideas, la hipótesis 4 también fue aceptada. Los resultados evidenciaron una importante vinculación entre la medición de propiedades de inversión y propiedades, planta y equipos, a valor razonable y la dependencia de la deuda financiera. En este caso, los factores determinantes en la utilización del valor 
razonable son el acceso a los mercados de deuda y el apalancamiento financiero.

Christensen y Nikolaev (2013) puntualizan que el criterio valorativo del costo histórico resulta aventajado cuando el entorno incide en la decisión de la gerencia respecto a la valoración de activos no financieros. $\mathrm{Al}$ respecto, indican:

Si bien nuestra evidencia sugiere que la oferta del mercado (costos) y la demanda (beneficio) son factores que influyen en la elección del valor razonable en comparación con la contabilidad del costo histórico, el costo histórico es, por mucho, la práctica contable dominante cuando las fuerzas del mercado determinan el resultado de la elección ${ }^{17}$ (p. 737).

\subsection{El trabajo de Vicente, Molina y Ramírez (2013)}

La investigación de Marta de Vicente, Horacio Molina y Jesús Ramírez (2013) se centró en el análisis de los factores que conducen a la elección del modelo del costo o del valor razonable, en la valoración posterior de las propiedades de inversión; el estudio se enmarcó en la teoría de la agencia.

Los académicos trabajaron con una muestra de sesenta y un (61) estados financieros, pertenecientes a grupos consolidados españoles (no vinculados al sector financiero ni al asegurador) que están registrados en la Comisión Nacional del Mercado de Valores (CNMV) y que presentan en sus estados de situación financiera el grupo de activos no corrientes cate-

17 Traducción libre del inglés al castellano. gorizado como propiedades de inversión. Los períodos económicos susceptibles a la investigación comprenden las fechas de reporte de $2005^{18}$ a 2007.

Para conducir con éxito su trabajo científico, los tratadistas emplearon, en primera instancia, un análisis univariante tendiente a evaluar el grado de asociación individual entre cada una de las variables consideradas y el modelo o criterio valorativo seleccionado. En segunda instancia, recurrieron a un análisis multivariante, específicamente a la regresión logística, con el propósito de determinar la incidencia de todo el conjunto de variables sobre la elección del modelo de valoración.

Por su parte, el estudio empírico giró alrededor de cuatro (4) hipótesis, basadas en elementos relativos a las asimetrías de información entre los distintos agentes, la importancia de las propiedades de inversión en el estado de situación financiera y la incidencia de la acepción del valor razonable en la valoración de propiedades de inversión.

La hipótesis $1_{\mathrm{a}}$ se encaminó a comprobar que los grupos cotizados españoles, con una marcada orientación a la actividad inmobiliaria, son más propensos a utilizar el valor razonable como criterio de valoración para sus propiedades de inversión, con el propósito de atraer inversores internacionales y aminorar las asimetrías de información existentes. En este contexto, la hipótesis $1_{\mathrm{a}}$ era la siguiente: "H1 $1_{\mathrm{a}}$ : la probabilidad de que la empresa opte por el criterio de valor razonable es mayor para las empresas pertenecientes al sector in- 
mobiliario" (De Vicente, Molina \& Ramírez, 2013, p. 32).

La hipótesis $1_{\mathrm{b}}$ pretendió demostrar la relación existente entre el peso de las propiedades de inversión (respecto al activo total de la entidad) y el uso del valor razonable. Los autores enfatizaron que, bajo la premisa de asimetrías de información, las entidades que contaron con una alta proporción de activo representada por propiedades de inversión eran más sensibles a la aplicación del valor razonable. Por lo tanto, la hipótesis $1_{b}$ indicó: " $\mathrm{H} 1_{b}$ : la probabilidad de que la empresa opte por el criterio de valor razonable es mayor cuanto mayor sea la importancia de sus inversiones inmobiliarias en el balance de situación" (De Vicente, Molina \& Ramírez, 2013, p. 33).

La hipótesis 2 procuró evidenciar que la valoración a valor razonable de propiedades de inversión permitía, probablemente, mostrar un mejor rendimiento económico y una posición financiera más sólida. Los académicos puntualizan que, en épocas de crecimiento del sector inmobiliario, la valoración de propiedades de inversión impacta positivamente en los resultados empresariales $y$, por ende, en la estructura financiera. En este sentido, la hipótesis 2 revela: "H2: la probabilidad de que la empresa opte por el criterio de valor razonable es mayor cuanto mayor sea el impacto del valor razonable sobre el total de activos" (De Vicente, Molina \& Ramírez, 2013, p. 34).

La hipótesis 3 intentó probar la existencia de una relación entre el nivel de endeudamiento y la aplicación del valor razonable en las propiedades de inversión. Los autores sostienen que la valoración a valor razonable, en un escenario económico favorable, incide en la cuantía de la ratio de endeudamiento y exhibe una disminución del riesgo financiero de incumplimiento. En conexión, la hipótesis 3 puntualizó: "H3: la probabilidad de que la empresa opte por el criterio de valor razonable es mayor cuanto mayor sea su nivel de endeudamiento" (De Vicente, Molina \& Ramírez, 2013, p. 35).

La hipótesis 4 se orientó a reconocer la relación entre el nivel de concentración de la propiedad y el uso del valor razonable. Los tratadistas aseveraron que, en estructuras de propiedad más dispersas, resulta probable el empleo, por parte de la gerencia, de criterios contables que aceleren el reconocimiento de ingresos, lo que acrecienta de forma directa su retribución basada en beneficios. Por consiguiente, la hipótesis 4 indicó: “H4: la probabilidad de que la empresa opte por el criterio de valor razonable es mayor cuanto más dispersa sea su estructura de propiedad" (De Vicente, Molina \& Ramírez, 2013, p. 35).

Los resultados obtenidos por Marta de Vicente, Horacio Molina y Jesús Ramírez (2013) en el análisis univariante, puntualizaron que el sector tiene una influencia significativa sobre la elección del modelo contable. Estos resultados confirmaron la hipótesis $1_{a}$.

De igual forma, la hipótesis $1_{b}$ fue aceptada, pues era consistente tanto en el análisis univariante como en el multivariante. Efectivamente, los grupos cotizados españoles que optan por el valor razonable presentan un importe de sus propiedades de inversión (en proporción con el activo total) más elevado que las entidades que optan por el costo histórico. Los 
autores replican que el resultado proveniente de la gestión de una propiedad de inversión, en empresas del sector inmobiliario, está integrado por dos componentes, a saber: el ingreso por arrendamiento y los cambios por valor razonable.

Por su parte, la hipótesis 2 fue rechazada. A pesar de que la incidencia del valor razonable se incrementó del 5\% en 2005 a 11\% en 2007, el análisis multivariante ostentó un coeficiente con signo contrario a la predicción. Esta situación indicó que cuanto mayor es el impacto del valor razonable en el total de los activos, la entidad está menos dispuesta a emplear este criterio de medición.

Para las hipótesis 3 y 4, los académicos no lograron obtener evidencia empírica que respaldara las predicciones planteadas. Sin embargo, los niveles de endeudamientos aumentaron desde 2,49 en 2005 a 2,93 en 2007. Finalmente, la dispersión accionaria se redujo de $51 \%$ en 2005 a 43\% en 2007.

Para concluir este apartado, conviene precisar que la decisión de optar por el modelo del valor razonable o por el costo histórico, en la valoración de las propiedades de inversión, no está vinculada con ciertos problemas de la agencia. Al respecto, De Vicente, Molina y Ramírez (2013) señalan:

Nuestros resultados ponen de manifiesto que esa elección persigue reducir las asimetrías de información existentes y no está asociada con algunos mecanismos de control de los problemas de agencia, como el endeudamiento y la estructura de la propiedad (p. 48).

\section{Tratamiento contable de los activos no financieros en las NIIF (2014)}

Los activos no financieros considerados en la investigación son los que integran los grupos de propiedades, planta y equipo y propiedades de inversión. A continuación, se puntualiza el tratamiento contable dispuesto en las NIIF (2014), relativo a valoración, para cada uno de los activos no financieros seleccionados en el estudio.

\subsection{Propiedades, planta y equipo}

La NIC 16 (2014) en su párrafo 23 estipula que un elemento de propiedades, planta y equipo, en el momento de su reconocimiento inicial, debe ser medido a su costo histórico, que es el equivalente al precio en efectivo cancelado para su adquisición.

Asimismo, el párrafo 24 de la NIC 16 (2014) establece que un activo de propiedades, planta y equipo puede adquirirse o recibirse por medio de una operación de permuta financiera. En este tipo de transacción, el activo recibido debe medirse a su valor razonable, a menos que la permuta no posea un carácter comercial o el valor razonable del bien recibido o entregado no pueda ser medido con fiabilidad. Para estas últimas situaciones, se empleará como valor el importe en libros del bien entregado. El párrafo 26 de NIC 16 (2014) indica que el valor razonable de un activo puede medirse con fiabilidad cuando se materializa una de las siguientes condiciones:

(a) La variabilidad en el rango de las mediciones del valor razonable del activo no es 


\section{MEDICIÓN DE ACTIVOS NO FINANCIEROS / H. CASTELLANOS / 53}

significativa, o (b) las probabilidades de las diferentes estimaciones, dentro de ese rango, pueden ser evaluadas razonablemente y utilizadas en la medición del valor razonable (p. 707).

Si la entidad tiene la capacidad de obtener el valor razonable del activo recibido y del activo entregado, deberá utilizar el importe razonable del activo recibido, salvo que la medida del activo entregado aminore la incertidumbre del proceso de medición.

En cuanto a la valoración posterior, la gerencia de la entidad deberá seleccionar entre el modelo del costo y el modelo de la revaluación (valor razonable). Optar por un modelo de valoración en detrimento del otro, se considerará como una política contable ${ }^{19}$.

El modelo del costo, descrito en el párrafo 30 de la NIC 16 (2014), expone que la valoración, en cada fecha en la que se informa, de los elementos de propiedades, planta y equipo se hará conforme a su costo histórico, deducido de él la depreciación acumulada y las pérdidas acumuladas por deterioro ${ }^{20}$.

Por su parte, el párrafo 31 de la NIC 16 (2014) especifica que el modelo de la revaluación podrá ser aplicado, a criterio de la gerencia de la entidad, en cada fecha sobre la que se informa, siempre que el valor razonable del activo no financiero pueda medirse con suficiente

19 La NIC 8 (2014) "Políticas contables, cambios en las estimaciones contables y errores" norma la aplicación y posibles cambios en las políticas contables que adopte la gerencia de la entidad.

20 La NIC 36 (2014) "Deterioro del valor de los activos" prescribe el tratamiento contable relativo al deterioro de valor de los elementos de propiedades, planta y equipo. fiabilidad. Por esta metodología, el importe a presentar en el estado financiero será el valor revaluado, que comprende el valor razonable menos la depreciación acumulada y el deterioro acumulado.

Cuando la gerencia seleccione el método de la revaluación deberá revisar el importe periódicamente, a fin de asegurar que su cuantía real no se distancie del importe en libros informado en la última fecha de presentación. No obstante, la frecuencia de la revaluación obedecerá a su grado de susceptibilidad por exposición al mercado y se puede requerir de forma anual o en períodos superiores.

Una de las condiciones sine qua non que prevé el párrafo 36 de la NIC 16 (2014) para aplicar la metodología de la revaluación es que se deben revaluar todos los elementos de propiedades, planta y equipo que pertenezcan a la misma clase de activos. Así, por ejemplo, en caso de que la gerencia de la entidad decida revaluar una de sus aeronaves, estará obligada a revaluar todas las aeronaves que controle y presente en sus estados financieros en el renglón de propiedades, planta y equipo.

$\mathrm{Al}$ momento de contabilizar la revaluación de un activo de propiedades, planta y equipo, será necesario analizar dos variables, con el propósito de aplicar correctamente el tratamiento contable que prescriben los párrafos 39 y 40 de la NIC 16 (2014). La primera se orienta a conocer si el cambio de valor, ocasionado por la revaluación, provoca un aumento o una disminución en el importe en libros del activo y, la segunda se vincula a determinar si ese cambio de valor es consecuencia de una 
reversión de un valor reconocido en un período anterior.

El tratamiento contable que dispone NIC 16 (2014) indica que si el procedimiento de revaluación produce un incremento en el valor del activo, este debe reconocerse en el componente de otros resultados integrales, a menos que el alza del importe esté relacionada con una reversión de una pérdida de valor reconocida en períodos anteriores, por lo que la variación se incorporará al resultado operacional.
En contraste, si la revaluación ocasiona una disminución en el valor del activo, este debe reconocerse directamente en los resultados operacionales, a menos que la baja del importe esté relacionada con una reversión de una ganancia reconocida en períodos anteriores, por lo que la variación se incorporará al componente de otro resultado integral.

El gráfico 2 detalla el procedimiento contable que debe seguirse al optar por el modelo de la revaluación.

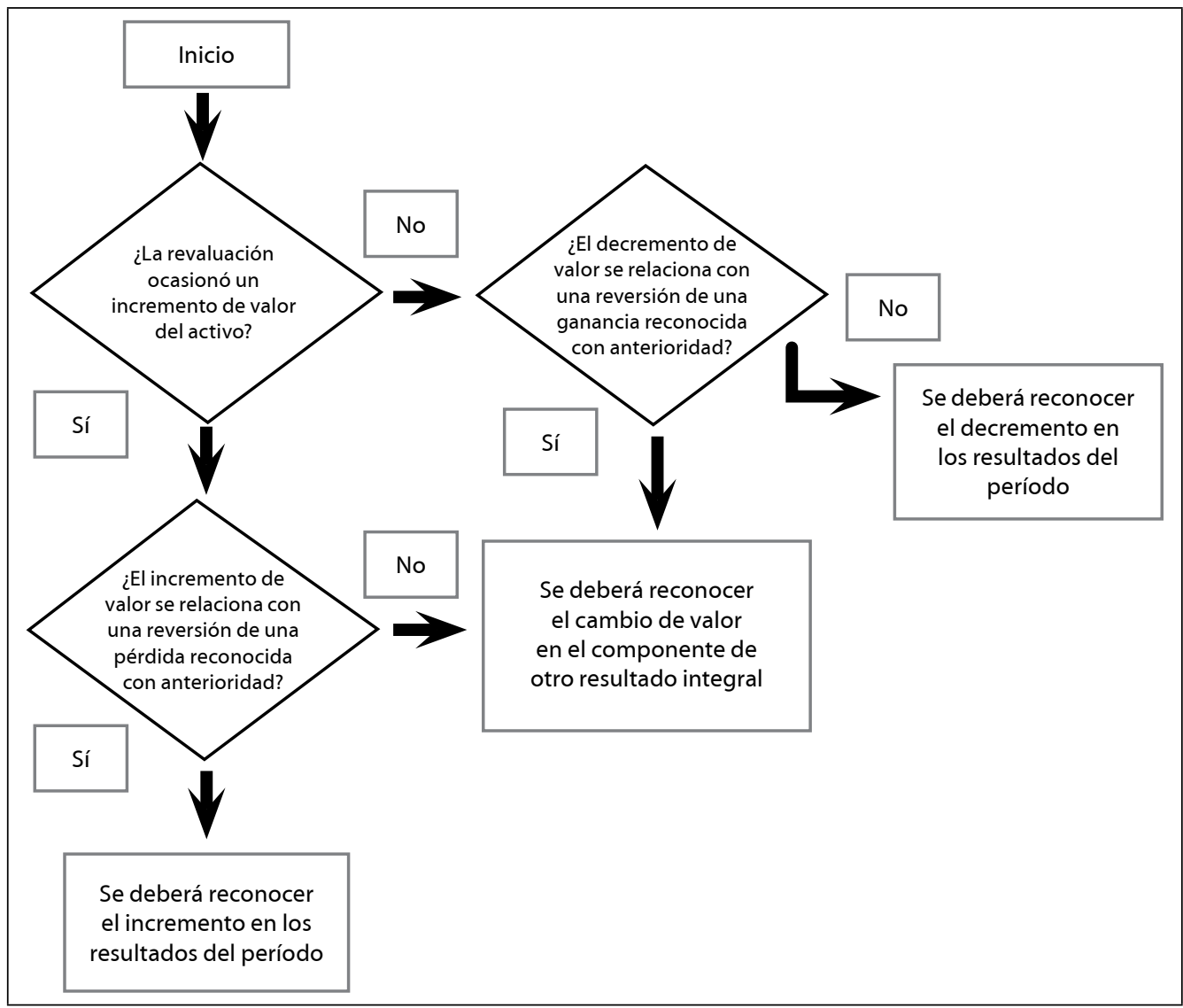

Gráfico 2. Tratamiento contable dispuesto por la NIC 16 (2014) para la revaluación de activos Fuente: elaboración propia 


\subsection{Propiedades de inversión}

La NIC 40 (2014) en su párrafo 20 establece que un activo categorizado como propiedad de inversión será valorado inicialmente al costo histórico, incluidas las erogaciones directamente atribuibles a la transacción de adquisición.

Los párrafos del 27 al 29 de la NIC 40 (2014) prescriben el procedimiento contable para medir, al momento del reconocimiento inicial, un elemento de propiedad de inversión que absorba la entidad como resultado de una transacción de permuta financiera. Las consideraciones expuestas en estos incisos no discrepan, en absoluto, de lo señalado en el apartado anterior para las propiedades, planta y equipos.

En relación con la medición posterior, en su párrafo 30, la NIC 40 (2014) puntualiza, con cierta excepción, que la gerencia de la entidad debe establecer como política contable, la medición al valor razonable o al costo histórico para todos los activos que conformen el grupo de propiedades de inversión. En otras palabras, al optar por uno de los dos criterios, todos los elementos del renglón de propiedades de inversión deben ser valorados a partir de la misma acepción valorativa.

La excepción mencionada está prevista en el párrafo 32A y se orienta a permitir la aplicación del modelo del valor razonable o del modelo del costo, únicamente, a activos de propiedad de inversión que respalden la cancelación de obligaciones que dependan de un retorno vinculado al valor razonable de uno o varios activos. Esta particularidad implica que los activos que garantizan el cumplimiento de deudas podrían estar valorados sobre la base de un criterio y los demás en función de otro.
Una vez seleccionado el modelo del valor razonable para medir las propiedades de inversión en cada fecha en la que se informa, la NIC 40 (2014), en su párrafo 40, indica que la entidad debe destinar sus esfuerzos a calcular un importe que integre todos los supuestos que los participantes del mercado emplearían para establecer el precio del inmueble, incluidos los beneficios por cánones de arrendamientos actuales.

Un aspecto destacado sobre el modelo del valor razonable revela que la NIC 40 (2014) insta a la gerencia de la entidad a obtener el importe razonable de una propiedad de inversión con la opinión de un experto independiente en una transacción de tasación. Sin embargo, el párrafo 32 deja abierta la posibilidad de utilizar otros métodos financieros alternativos, por lo que solo se traduce en una recomendación del IASB (2014).

Una marcada diferencia, al aplicar el modelo del valor razonable, entre el tratamiento contable de una propiedad, planta y equipo y el de una propiedad de inversión se vincula al destino de la partida que reconoce el cambio del valor razonable de un bien. De tal manera que la variación de valor de una propiedad de inversión deberá, sin excepción alguna, reconocerse en los resultados del período.

Al medir un elemento de propiedad de inversión a partir de la acepción de valor razonable, no será necesaria la estimación de la depreciación, ni del valor de salvamento.

Por último, las disposiciones relativas al modelo del costo que se detallan en el párrafo 56 de la NIC 40 (2014) refieren al tratamiento contable que prevé la NIC 16 (2014) en su inciso 
30, ya explicado en la sección anterior. Al seleccionar el modelo del costo, la entidad deberá incorporar en la información a revelar el valor razonable de las propiedades de inversión.

\subsection{Máximo y mejor uso de los activos no financieros}

La NIIF 13 (2014) exhorta a la gerencia de la entidad a obtener el valor razonable de un activo no financiero en un contexto congruente con su máximo y mejor uso. Esta premisa valorativa, descrita en el párrafo 27, se indica a continuación:

Una medición a valor razonable de un activo no financiero tendrá en cuenta la capacidad del participante de mercado para generar beneficios económicos mediante la utilización del activo en su máximo y mejor uso o mediante la venta de este a otro participante de mercado que utilizaría el activo en su máximo y mejor uso (p. 492).

El máximo y mejor ${ }^{21}$ uso presume la determinación del importe que los participantes del mercado asignarían a un activo no financiero utilizado de la forma más rentable posible, en las condiciones físicas y restricciones legales que lo caractericen. A este efecto, estaría latente la posibilidad de que el máximo y mejor uso del activo fuese distinto al uso previsto por la entidad a la fecha sobre la que se informa.

La NIIF 13 (2014), en su párrafo 31, prescribe que el máximo y mejor uso de un activo no financiero se puede computar en forma aislada (si su uso no depende ni está en conexión

21 Para un mayor grado de detalle, consultar los párrafos del 27 al 33 y el B3 de la NIIF 13 (2014). con otros activos), o en combinación con un grupo de activos y/o pasivos (si su utilización está concatenada con más activos). En este último caso, el valor razonable del activo no financiero hace referencia al importe que se recibiría al enajenar el bien, bajo la conjetura de que, en poder del adquiriente, funcionaría en unión con activos y/o pasivos similares y en un escenario en que los participantes del mercado tendrían acceso a los activos y/o pasivos complementarios.

\section{Elementos que intervienen en la decisión de la gerencia al optar por el modelo del valor razonable}

\subsection{La relevancia de la información financiera}

En el actual enfoque regulador, el constructo contable de relevancia se define como una característica cualitativa fundamental de la información financiera útil. Al respecto, el Marco conceptual para la información financiera (2014) define, en su párrafo CC6, la relevancia como:

\footnotetext{
La información financiera relevante es capaz de influir en las decisiones tomadas por los usuarios. La información puede ser capaz de influir en una decisión incluso si algunos usuarios eligen no aprovecharla o son ya conocedores de ella por otras fuentes (p. 34).
}

Con las constantes revisiones y subsiguientes modificaciones realizadas al Marco conceptual en 2011, la acepción de relevancia ha trascendido 
entre las distintas características cualitativas y ha adquirido gran importancia. El gráfico 3 ilustra la comparación de las disposiciones normativas, referentes a las características cualitativas principales y fundamentales, contenidas en el Marco conceptual para la preparación y presentación de estados financieros (2010) y en el Marco conceptual para la información financiera (2014).

Como se puede observar en el gráfico 3, el Marco conceptual para la información financiera (2014) establece como características cualitativas fundamentales los constructos de relevancia y de representación fiel. Esto implica que "si la información financiera ha de ser útil, debe ser relevante y representar fielmente lo que pretende representar" (IASB, Marco conceptual, 2014, párrafo CC4). No obstante, entre ambas características fundamentales prevalece la relevancia, lo cual justifica esta aserción en su proceso de aplicación. En este sentido, el Marco conceptual para la información financiera (2014), en su párrafo CC18, detalla las fases de aplicación de las características cualitativas fundamentales de la siguiente manera:

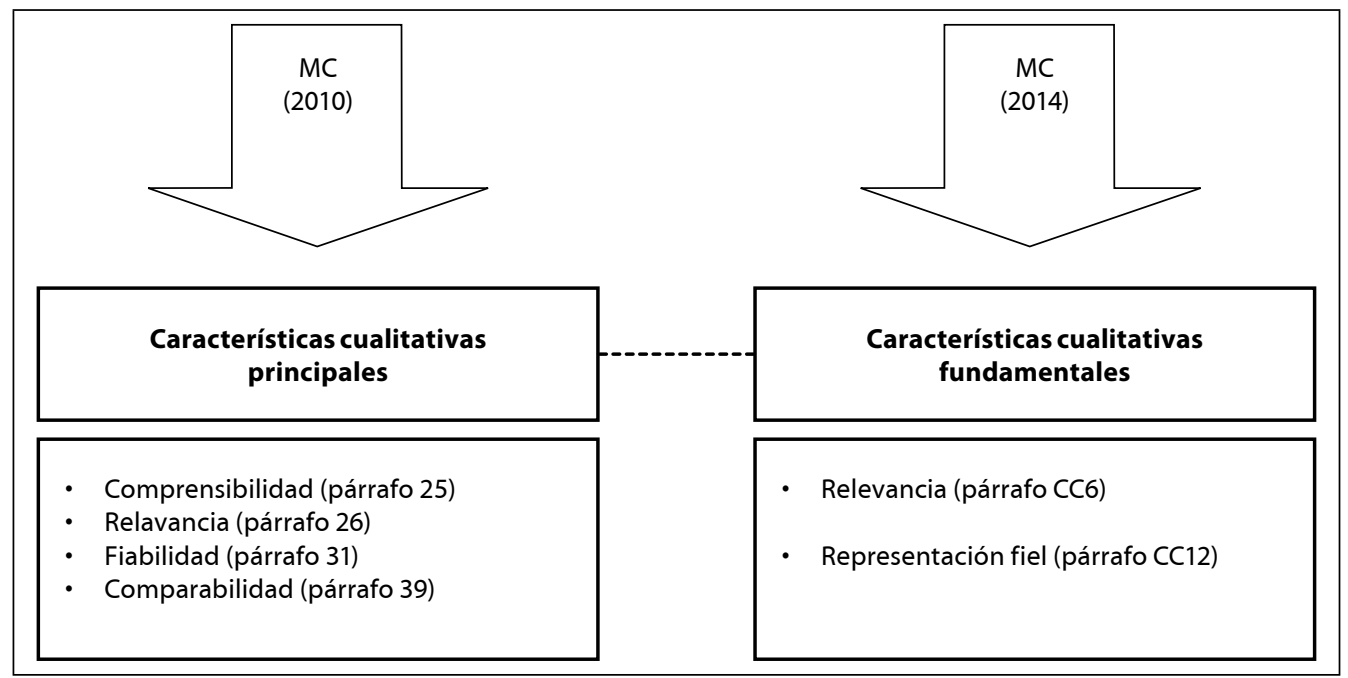

Gráfico 3. Características cualitativas principales en el Marco conceptual (2010) y fundamentales en el Marco conceptual (2014)

Fuente: elaboración propia

Primero, identificar un fenómeno econó-

mico que tiene el potencial de ser útil a los

usuarios de la información financiera de la

entidad que informa. Segundo, identificar el

tipo de información sobre ese fenómeno que

sería más relevante si se encontrara dispo-

nible y pudiera ser representada fielmente.
Tercero, determinar si esa información está disponible y puede ser representada fielmente (p. 36).

Al examinar la aplicación de las características cualitativas fundamentales de la información financiera se deduce que las dos primeras 
fases están inmersas en el constructo de relevancia. El preparador de la información debe contar con la capacidad de identificar las necesidades actuales y potenciales de los usuarios, a fin de canalizar la información financiera a presentar.

Ahora bien, el Marco conceptual para la información financiera (2014, p. 36) explica, en su párrafo CC17, que "ni una representación fiel de un fenómeno irrelevante ni una representación no fidedigna de un fenómeno relevante ayudan a los usuarios a tomar decisiones adecuadas". Esta aseveración, a juicio propio, no debe ser aceptada como cierta en su totalidad. La explicación se sustenta en la información cualitativa o narrativa que se revela en los estados financieros. Evidentemente, una información relevante pero poco fidedigna puede convertirse en una fuente potencial de equívocos para las decisiones de los usuarios interesados. Sin embargo, si esa información, identificada como relevante, no es susceptible de cuantificación, pero se presenta en las notas explicativas como otra información adicional, podría causar impacto positivo en las percepciones de los usuarios.

A título de ejemplo, se mencionan los activos y pasivos contingentes ${ }^{22}$, los cuales hacen referencia a recursos y obligaciones que poseen asociados un importante grado de incertidumbre sobre sus posibles entradas o salidas de recursos que incorporan beneficios económicos futuros y acerca de la representación fiel de su cuantía. Estos elementos deben ser comunicados en las notas explicativas de los estados

22 Regulados por la NIC 37 (2014) "Provisiones, Pasivos Contingentes y Activos Contingentes". financieros y, por supuesto, influirán en las decisiones de los destinatarios. Como se puede apreciar, "la información sobre los riesgos e incertidumbres, que tienen una proyección futura, aporta relevancia a la información" (Benavente, 2010, p. 25).

$\mathrm{Al}$ considerar que el suministro de información relevante es directamente proporcional a las necesidades de los usuarios, podría inferirse que la información financiera reportada por una entidad será catalogada de relevante por ciertos usuarios pero de irrelevante por otros. Sobre este particular, Álvaro Javier RomeroLópez (2007, p. 99) indica que la característica cualitativa de relevancia "es un tanto subjetiva, por lo que deberá responder a las necesidades de información", en suma, un usuario apreciará una información relevante cuando esté vinculada al proceso de toma de decisiones.

A pesar de que cada usuario de la información financiera tiene requerimientos específicos y resulta ambicioso atender todas sus necesidades, el Marco conceptual para la información financiera (2014) delimita, en sus párrafos OB2 al OB5, como principales usuarios a los actuales y posibles inversores, prestamistas y acreedores. En otras palabras, a ellos se dirigen los informes financieros.

Por otra parte, la dicotomía valorativa permisible para activos no financieros ha fomentado el debate contable para conocer cuál sería la acepción de medición más adecuada a ser aplicada en el reconocimiento posterior. Esta discusión gira en torno a las características cualitativas de relevancia y representación fiel. En este orden de ideas, Marta de Vicente, Horacio Molina y Jesús Ramírez (2009) indican que el 
costo histórico es un modelo fundamentado en la representación fiel y el conservadurismo, mientras el modelo del valor razonable se basa en la relevancia.

No obstante, Thomas Linsmeier (2013, p. 779), directivo del FASB ${ }^{23}$, agrega "el costo histórico no siempre puede ser considerado más fiable que el valor razonable ${ }^{24 ”}$. El autor enfatiza que la medición posterior a costo histórico está supeditada a numerosas estimaciones contables, como la determinación de patrones de consumo de beneficios económicos, vidas útiles, valores de salvamento e indicadores de deterioro, entre otras.

En este sentido, Guillaume Plantin, Haresh Sapra y Song Hyun Shin (2008) mencionan que la medición a costo histórico no dista de la medición a valor razonable cuando los activos disminuyen su valor a la fecha sobre la que se informa. Un valor razonable menor al costo histórico se traduce en deterioro del valor de los activos. Esta situación se manifiesta en que para el cálculo del deterioro de valor de activos no financieros se requiere determinar el importe recuperable, concebido este como el mayor entre su valor de uso (valor actual de los flujos futuros estimados de efectivo asociados al activo) y su valor razonable menos costo de disposición.

En síntesis, caracterizar el valor razonable como una medida poco representativa de la realidad no puede convertirse en un axioma contable. Por el contrario, hay evidencia de que, en

23 Por sus siglas en inglés Financial Accounting Standards Board, organismo estadounidense emisor de estándares contables.

24 Traducción libre del inglés al castellano. ciertas circunstancias, la característica cualitativa de representación fiel alcanza un estatus similar en mediciones tanto a valor razonable como a costo histórico.

Por su parte, Hans Bonde Christensen y Valeri V. Nikolaev (2013) señalan que en la última década, tanto el FASB como el IASB han favorecido la relevancia sobre la representación fiel y se manifiestan permanentemente en el tránsito a una contabilidad basada en el valor razonable. $\mathrm{Al}$ respecto, mencionan los académicos que, en un debate sobre relevancia y fiabilidad llevado a cabo en 2005, Todd Johnson, gerente de proyecto del FASB, explicó:

La Junta ha exigido un mayor uso de mediciones del valor razonable en los estados financieros, ya que percibe la información como más relevante para los inversores y los acreedores que la información de costos históricos. Estas medidas reflejan mejor el estado financiero de las entidades informantes y facilitan la evaluación de su desempeño pasado y las perspectivas futuras. En ese sentido, el Consejo no acepta la opinión de que la fiabilidad debe pesar más que la relevancia para las medidas de los estados financieros ${ }^{25}$ (L. Todd Johnson, 2005, citado por Christensen \& Nikolaev, 2013, p. 741).

Un caso específico que reafirma la postura de Hans Bonde Christensen y Valeri V. Nikolaev (2013) es el de las propiedades de inversión. La NIC 40 (2014) requiere la determinación del valor razonable, aun cuando la política contable obedezca al modelo del costo (las revelaciones

25 Traducción libre del inglés al castellano. 
deben incluir el valor razonable del activo). La preferencia por las mediciones a valor razonable, de acuerdo al documento Fundamentos de las conclusiones de la NIC 40 Propiedades de inversión, se vincula a la supremacía de los importes razonables, en términos de utilidad. Sobre este particular, el mencionado escrito explica:

\footnotetext{
Los ingresos por arrendamiento y los cambios en el valor razonable están indisolublemente ligados como componentes integrales del rendimiento financiero de una propiedad de inversión, y la medición al valor razonable es necesaria si se va a reportar tal rendimiento financiero de forma que resulte significativa (IASB, Fundamentos de la NIC 40, 2014, párrafo B44).
}

Conectando con el objetivo general de la investigación, los elementos de la gerencia, utilizados para medir a valor razonable activos no financieros, deben estar concatenados con las necesidades de los usuarios principales de la información financiera (inversores, prestamistas y acreedores).

\subsection{Disponibilidad de valores} razonables y costo de obtención asociado

Indiscutiblemente, la preparación y presentación de información financiera genera costos económicos para la entidad emisora e incluso, para el usuario receptor de esa información. Este escenario es reconocido por el IASB en el Marco conceptual para información financiera (2014), con el desarrollo del apartado "la restricción del costo en la información financiera útil". Esta disposición normativa puntualiza: "al aplicar la restricción del costo, el Consejo evalúa si los beneficios de presentar una información en particular probablemente justifican los costos incurridos para suministrar y utilizar esa información" (IASB, Marco conceptual, 2014, párrafo CC38).

Como se puede observar, la apreciación de la restricción del costo deriva en un acto eminentemente subjetivo, en virtud de la ausencia de parámetros cuantitativos y/o cualitativos para saber hasta qué punto los beneficios de uso exceden el costo de obtener e interpretar la información financiera.

En este contexto, numerosas entidades presentan resistencia a la contabilidad a valor razonable, en gran medida, por los considerables costos que supone su proceso de medición. Así lo ratifican las investigaciones del Banco de España (2008), Leandro Cañibano (2006), Julio César David (2010), María Antonia García-Benau y Ana Zorio-Grima (2002), Sara GonzálezLosantos (2012), José Antonio Gonzalo-Angulo (2009), Pedro Monge (2005), José MoralesDíaz (2010), y Berta Silva-Palavecinos y Digna Azua-Álvarez (2006).

$\mathrm{Al}$ no prescribir el uso de una técnica específica de valoración para alcanzar el objetivo de la medición a valor razonable, la permisividad de la NIIF 13 (2014) concede a la gerencia de la entidad la posibilidad de seleccionar, entre múltiples alternativas, la técnica que mejor se ajuste a la partida sometida a medición. Como lo explica la Fundación IFRS (2012, p. 8), la gerencia debe reconocer "dadas circunstancias específicas, que una técnica de valoración puede ser más apropiada que otra ${ }^{26 "}$.

26 Traducción libre del inglés al castellano. 
Este argumento, fundamentado en el empleo de diversas técnicas para obtener los valores razonables, ocasiona que las entidades incurran en desembolsos económicos relacionados, principalmente, con la capacitación del recurso humano, la implementación de un sistema de control interno y la necesidad de acudir a profesionales externos especializados que certifiquen o avalen los valores iniciales de las partidas, así como sus periódicas revisiones.

La formación del talento humano se ha convertido en un factor clave en las entidades que miden sus elementos contables a valor razonable. Las entidades deben invertir recursos económicos para proporcionar a su personal conocimientos concernientes al comportamiento y funcionamiento de mercados financieros, análisis de las variables que intervienen en la estructura de las técnicas de valoración, interpretación de la información financiera a valor razonable presentada por otras entidades, entre otras nociones.

En esta misma idea, José Antonio GonzaloAngulo (2009, p. 55) puntualiza que "cuando se utilizan precios de cotización, informes de valoración, fórmulas financieras de descuento de flujos y otros métodos propios de la valoración empresarial el coste de las personas responsables de los servicios contables aumenta, por la especialización y entrenamiento".

La implementación de un sistema de control interno, dirigido a aquellas entidades que midan sus elementos a valor razonable, resulta definitivamente imprescindible. Los procedimientos para la determinación de los importes deben estar íntegramente definidos, autorizados y auditados, para brindar al usuario confianza de las cifras contenidas en los estados financieros.

Por último, la persistencia de la NIIF 13 (2014) en la revisión periódica de los valores razonables para determinar la pertinencia de calibrar un modelo o de seleccionar otro, generalmente, implica la necesidad de que la entidad acuda a expertos externos para que colaboren en la obtención de los importes e, incluso, den fe pública de la veracidad de esas cifras. Sara Helena Otal-Franco y Ramiro Serrano-García (2006) exponen que en mediciones a valor razonable es común la contratación de tasadores externos. No obstante, la contratación de un profesional especializado se traduce en altos costos para la entidad. Por esto, la gerencia debe emitir un juicio al contrastar el costo del tasador independiente y el beneficio de confianza que su trabajo proporcionará a la información financiera.

$\mathrm{Al}$ respecto, la NIC 40 (2014) en su párrafo 32 recomienda, pero no exige, la medición a valor razonable de las propiedades de inversión sobre la base de una tasación independiente. La norma agrega que el experto debe contar con una reconocida trayectoria profesional y con una extensa experiencia (atributos que deben ser revelados). Sin embargo, quienes se opusieron a esta sugerencia normativa, basándose en la restricción del costo, manifestaron:

El IASB no debe exigir (y quizás ni siquiera promover) una tasación independiente. Creen que quienes elaboran la información son los que, en consulta con los auditores, deben decidir si una entidad tiene los recursos internos suficientes para determinar 
valores razonables fiables. Algunos también creen que en algunos mercados no existen tasadores independientes con la adecuada experiencia (IASB, Fundamentos de la NIC 40, 2014, párrafo B55).

Como se puede apreciar, la gerencia de la entidad deberá efectuar una evaluación discrecional para decidir si los beneficios obtenidos de determinar el valor razonable de un activo no financiero superan los costos incurridos en el proceso de medición.

\subsection{Medidas de desempeño}

En virtud de que los accionistas facultan a la gerencia para representarlos, estos pueden tomar decisiones que provean cuantiosos riesgos al capital invertido. A la luz de la teoría de la agencia de Michael Jensen y William Meckling (1994), la información financiera reportada por las organizaciones asume un rol preponderante en el control de las actividades y responsabilidades asignadas a la gerencia, convirtiéndose en un mecanismo cuantificador de la gestión empresarial.

El Marco conceptual para la información financiera (2014) plantea una aproximación a la premisa de Jensen y Meckling (1994), en su párrafo OB4, al indicar quela información financiera debe permitir a los actuales y potenciales acreedores, prestamistas e inversionistas evaluar "la medida en que la gerencia y el órgano de gobierno han cumplido eficiente y eficazmente con sus responsabilidades relacionadas con el uso de los recursos de la entidad".

Resulta oportuno explicar cuatro aspectos inherentes a las medidas de desempeño: medi- das de rentabilidad, medidas de endeudamiento, medidas del costo de oportunidad y modelo de negocio.

\subsubsection{Medidas de rentabilidad}

La elección entre el modelo del valor razonable y el modelo del costo, en la medición de activos no financieros, afecta las ratios de rentabilidad que se obtienen de la información presentada por las entidades.

Oriol Amat y Marcos Renart (2013) ilustran esta aseveración con el caso de una entidad que posee entre sus activos un edificio construido hace más de cien años, lo ha venido contabilizando por el método del costo y, en la actualidad, está totalmente depreciado. Recientemente, adquirió e instaló en el edificio un ascensor por 22.600 euros. Paradójicamente, el único importe reflejado en el estado de situación financiera es el correspondiente al ascensor. Como se puede observar, el modelo del costo ofrece al usuario una información que dista, en forma excesiva, de la realidad del activo no financiero, lo que podría incidir negativamente en las ratios sobre rentabilidad.

En el caso de la rentabilidad de los activos se pueden examinar dos situaciones. La primera es la vinculada con la razón de ventas netas entre activos totales; esta es una medida de rentabilidad que indica "el grado de eficiencia con que una empresa utiliza sus activos para generar ventas" (Estupiñán \& Estupiñán, 2008, p. 151). La valoración a valor razonable que provoca alzas en los importes de los activos disminuye este indicador financiero, por lo cual se presumiría que la gerencia subutiliza los activos. Este escenario no es apreciado por la ge- 
rencia debido a que, en numerosas ocasiones, cuentan con incentivos económicos en función a la rentabilidad empresarial.

La segunda se relaciona con el índice de rentabilidad del activo total (utilidad neta entre activo total promedio), "esta razón muestra la capacidad del activo para producir utilidades, independientemente de la forma como haya sido financiado, ya sea con deuda o patrimonio" (Ortiz, 2008, p. 233). Este indicador se verá afectado por una medición a valor razonable, únicamente, cuando la contrapartida del cambio en el valor del activo deba reconocerse en los resultados integrales ${ }^{27}$. Concretamente, la utilidad neta no está afectada por la variación del importe, pero el activo total sí contiene el efecto del valor razonable. En contraste, cuando el cambio en el valor razonable se reconoce directamente en los resultados del período, tanto la utilidad neta como el activo total están impregnados de los cambios en el valor razonable.

No obstante, el reconocimiento en resultados del cambio en el valor razonable de un activo sí tiene impacto en el cómputo de otros indicadores financieros. A título de ejemplo, se enuncia la ratio de utilidad por acción común (utilidad neta entre el número de acciones comunes en circulación). Al analizar la razón financiera se deduce que, en tiempos de alzas de

27 En el caso de activos no financieros, este tratamiento solo es aplicable a propiedades, planta y equipos, y en dos circunstancias específicas, como exponen los párrafos 39 y 40 de la NIC 16 (2014). La primera se refiere a activos que incrementen su importe en libros sin que previamente se haya reconocido una pérdida de valor. La segunda concierne a los recursos que disminuyan su valor como consecuencia de una reversión de una ganancia reconocida con anterioridad. precios, el usuario de la información percibirá una utilidad más elevada si los activos se miden a valor razonable.

Varios autores, como Heiberg Castellanos (2012), Dimitris Chorafas (2007), Manuel Conthe (2008), Domingo Marchese (2010), Gonzalo Rodríguez-Pérez y Magda Solà-Tey (2007), Berta Silva-Palavecinos (2011), argumentan que el reconocimiento en resultados del cambio en el valor razonable de los elementos contables debe ser tratado sagazmente. No debe obviarse que se está en presencia de resultados no realizados y, cuando estos posteriormente formen parte de las ganancias acumuladas en el patrimonio estarán disponibles para ser distribuidos en forma de dividendos. Al respecto, Gonzalo Rodríguez-Pérez y Magda Solà-Tey (2007) explican:

\begin{abstract}
Al generarse temporalmente en momentos diferentes según las alternativas escogidas, podemos distribuir parte del patrimonio neto derivado de las revalorizaciones antes de que efectivamente se produzcan estos beneficios en el momento de la venta, lo que puede llevar a la descapitalización de la empresa si posteriormente los incrementos de valor no se hacen efectivos (p.109).
\end{abstract}

Como se puede inferir, los usuarios de la información pueden concebir las altas utilidades como un estado financiero óptimo y pretender dividendos proporcionales al beneficio económico descrito en los reportes contables. En otras palabras, el valor razonable incide notablemente en la percepción de los usuarios sobre la rentabilidad empresarial. 


\subsubsection{Medidas de endeudamiento}

De acuerdo a Oriol Amat (2008, p. 82), "la evaluación del endeudamiento permite comprobar si los recursos obtenidos por la empresa mantienen un adecuado equilibrio entre la financiación propia y ajena". Precisamente, la ratio financiera de endeudamiento (pasivo total entre activo total) puede verse afectada significativamente con la aplicación de la acepción valorativa de valor razonable.

Al respecto, José Luis Hervás-Oliver (2005, p. 40) revela que a "mayor nivel de endeudamiento, más posibilidad de incumplimiento de los acuerdos de deuda y, en consecuencia, más probabilidad de actualizar para disminuir el ratio". De la aseveración del autor se infiere que cuando la ratio de endeudamiento es elevada, la gerencia tiene la posibilidad de reducirla al valorar sus activos a valor razonable, siempre y cuando, los importes en libros de los activos aumenten. La disminución de la ratio de endeudamiento tiene importantes implicaciones:

- La percepción de los inversionistas podría estar orientada a concebir una entidad menos propensa al riesgo, lo que repercute positivamente en la apreciación de la gestión empresarial.

- La percepción de los prestamistas involucraría una calificación de menor riesgo de incumplimiento, lo que ocasiona un menor costo de financiación para próximos pasivos. Asimismo, estaría latente una mayor posibilidad de acceder a potenciales deudas.

En definitiva, la gerencia puede estar tentada a medir sus activos no financieros a valor razonable para mejorar el indicador financiero de endeudamiento. A pesar de ello, la decisión no puede tomarse a la ligera, puesto que, según Ramón Alsina (2008), si la ratio es muy reducida es un síntoma de descapitalización.

\subsubsection{Medidas del costo de oportunidad}

La medición de activos no financieros a valor razonable permite a los inversionistas conocer el costo de oportunidad asociado a la tenencia de los activos. A tal efecto, Thomas Linsmeier (2013), Joshua Ronen (2012) y Marta de Vicente, Horacio Molina y Jesús Ramírez (2009) explican que los usuarios, al contar con información financiera elaborada a partir de valores razonables, pueden ser capaces de evaluar los beneficios a los que renuncia la entidad por no vender el activo en un momento determinado.

Incluso, Joshua Ronen (2012) menciona que cuando el marco normativo contable permite un tratamiento alternativo para una partida específica (costo versus valor razonable), la gerencia de la entidad debe decidir entre un modelo de rendición de cuentas sobre costo histórico o sobre costos de oportunidad.

En el caso de las propiedades de inversión, la NIC 40 (2014) exige a las entidades, incluso seleccionando el método del costo, la revelación del valor razonable de los activos. Si bien es cierto que el usuario tendría acceso al valor razonable del activo y podría intentar valorar el costo de oportunidad de mantenerlo, no podrá observar el impacto en los resultados del período por el cambio en el valor razonable. Al respecto, Marta de Vicente, Horacio Molina y Jesús Ramírez (2009, p. 73) indican que el costo histórico "distorsionaría la comparabilidad 
entre empresas del sector con activos inmobiliarios con antigüedades diferentes, siempre y cuando en estos períodos se hayan producido oscilaciones significativas en el precio de los inmuebles".

Aunado a ello, si se acepta la premisa presentada por la NIIF 13 (2014) que indica que un valor razonable refleja las expectativas que, al momento de fijar un precio, los participantes en el mercado tendrían en cuenta la aplicación del modelo del costo histórico no solo impediría a los usuarios el cálculo del costo de oportunidad sino que ocasionaría, implícitamente, asimetría de información.

Marta de Vicente, Horacio Molina y Jesús Ramírez (2012) sostienen este punto de vista, al aclarar que, si los actuales o potenciales inversores tienen acceso a la misma información financiera que los directivos y accionistas involucrados en el gobierno corporativo, se evitarían imperfecciones en el mercado. Efectivamente, cuando un usuario solo conoce información basada en el costo histórico, ignora numerosas variables de mercado que se necesitarían para examinar el costo de oportunidad de conservar el activo no financiero.

$\mathrm{Al}$ elegir el valor razonable como método de medición de un activo no financiero, la NIIF 13 (2014) establece que la obtención del importe razonable se realice en un contexto congruente con su máximo y mejor uso ${ }^{28}$. Esa disposición normativa coadyuvaría a la evaluación del costo de oportunidad por la tenencia de cada activo no financiero, por parte de los usuarios de la información financiera.

28 Para un mayor grado de detalle, consultar los párrafos del 27 al 33 y el B3 de la NIIF 13 (2014).
En resumen, cuando la gerencia de la entidad opta por la ejecución de mediciones a valor razonable para sus activos no financieros, les está permitiendo a los usuarios de la información, la determinación del costo de oportunidad y, automáticamente, aminora las posibles asimetrías que se generarían con la aplicación de modelo del costo.

\subsection{Perfil de la gestión empresarial}

$\mathrm{Al}$ momento de decidir entre la medición a valor razonable o al costo histórico, la gerencia debe tener presente su perfil de gestión del negocio. Una entidad que únicamente emplee el costo en la medición de sus activos no financieros, transmitirá a los usuarios de la información financiera la sensación de una gestión conservadora, resistente a los cambios suscitados en el entorno y con una importante aversión al riesgo.

Tomás Eguren-Galende, Óscar Elvira-Benito, Pablo Larraga-Benito (2009) explican que una gestión con un enfoque tradicional es enemiga de la volatilidad y de riesgos innecesarios, en sus propias palabras "buscan tranquilidad financiera”. A una gestión conservadora se contraponen las mediciones a valor razonable, especialmente por el reconocimiento de resultados no realizados.

La contabilización de ganancias o pérdidas no materializadas incorpora a los estados financieros un importante nivel de volatilidad y de riesgos, en virtud de que las variaciones del valor razonable no dependen, en gran medida, de la actuación de la empresa, sino que están condicionadas a variables externas de mercado.

En síntesis, en épocas de crecimiento de los sistemas económicos se reconocen significa- 
tivas ganancias, pero en tiempos de recesión se hace necesario el reconocimiento de cuantiosas pérdidas. Esta situación es denominada por el Banco de España (2008) como "efecto procíclico”, por Ángel Muñoz-Merchante (2009) como "efecto riqueza" y por Carlos Valle-Larrea (2009) como "efecto burbuja". Este escenario debe ser tratado con habilidad por la gerencia, para que de esa información financiera no se desprendan decisiones erradas.

Finalmente, la decisión de la gerencia concerniente a cómo medir sus activos no financieros podrá convertirse en un indicador de su forma de actuar en los diversos ámbitos de quehacer empresarial, aspecto estratégico fundamental al momento de atraer nuevos inversionistas, entre otros objetivos.

\section{Reflexiones finales}

Ciertamente, cuando la gerencia de una entidad selecciona un método de medición en particular, incide, en gran medida, en el análisis e interpretación que los usuarios interesados hacen del comportamiento financiero de la entidad que reporta. Por esto, en el momento de definir sus políticas contables, el objetivo de la gerencia debe estar alineado con las necesidades de quienes hacen uso de los estados financieros. En síntesis, la gerencia debe favorecer, ante todo, la relevancia de la información.

La evaluación de la restricción del costo es un elemento que se le adiciona a la decisión de la gerencia. La aplicación de la acepción del valor razonable genera costos económicos que deben ser contrastados con los beneficios que proporcionará esta categoría de medición. Ante la ausencia de parámetros cualitativos y/o cuantitativos, el examen de la restricción del costo se convierte en un proceso de juicio profesional.

Resulta fundamental que la decisión de la gerencia, relacionada con la elección del valor razonable como política contable de medición para sus activos no financieros, esté acompañada de un minucioso estudio de las implicaciones que se podrían desencadenar. Como se observó en el desarrollo de la investigación, la medición al valor razonable impacta en la percepción de los usuarios de la información financiera, principalmente, en temas como rentabilidad, endeudamiento, costo de oportunidad y perfil de la gestión empresarial.

Una vez que el lector realiza un recorrido por los elementos que intervienen en la decisión de la gerencia para medir sus activos no financieros, resulta lógico obtener una percepción que indique que la gerencia puede valerse del marco normativo internacional para sesgar o perjudicar a un usuario en particular (como las medidas de rentabilidad, endeudamiento y costo de oportunidad). Sin embargo, la actividad de manipulación de cifras contables es obstaculizada por el precompromiso que establecen las NIIF (2014) de elegir como política contable un método de medición en particular, pues exige una justificación y cuantificación retroactiva al modificar la política inicialmente seleccionada.

Para concluir, se propone a la comunidad contable el desarrollo de trabajos investigativos orientados a validar los elementos intervinientes en la decisión de la gerencia para medir sus activos no financieros que se desarrollaron en el presente artículo científico. Resultaría de es- 
pecial interés la ejecución del estudio propuesto en entidades latinoamericanas, debido a que los antecedentes en el tema están relacionados con estudios en la Unión Europea.

\section{Referencias}

Alsina, Ramón (2008). Aplicación en Excel para el análisis de balances. Barcelona: Bresca Editorial.

Amat, Oriol (2008). Análisis integral de empresas. Barcelona: Bresca Editorial.

Amat, Oriol \& Renart, Marcos (2013). Fiabilidad de la información contable relativa al activo no corriente: algunos problemas y propuestas de mejora. Boletín de Estudios Económicos, 68 (208), 23-38.

Banco de España (2008). La generalización del valor razonable a los instrumentos financieros: un análisis de impacto y algunas implicaciones. Disponible en: http://www. normativafinanciera.com/normafin/ hemero.nsf/0/a1df946c7edebe83c125745f0 033a677/\$FILE/Generalizacion_del_valor_ razonable_12-05-08_IVI.pdf,

Benavente-Martínez, María del Carmen (2010). Análisis del impacto de la aplicación del valor razonable en la contabilidad de las empresas agrícolas y ganaderas. Trabajo de grado de doctorado no publicado, Universidad Nacional de Educación a Distancia. Disponible en: http://e-spacio.uned.es:8080/fedora/get/ tesisuned:CiencEcoEmp-Mcbenavente/ Documento.pdf

Cañibano, Leandro (2006). La reforma contable implicará cambios en profundidad y necesidad de capacitación a los profesionales. Partida Doble, 181, 10-14. Disponible en: http://www.aeca.es/entrevista_canibano_ partidadoble.pdf

Casinelli, Hernán (2008).La globalización del lenguaje de los negocios. Buenos Aires: Aplicación Tributaria S.A.

Castellanos, Heiberg (2012). Estudio crítico del valor razonable. Una reflexión de su incidencia en la calidad de la información financiera. Trabajo de grado de maestría no publicado, Universidad de los Andes de Venezuela. Disponible en: http://pcc. faces.ula.ve/Tesis/Maestria/Heiberg\%20 Castellanos/P\%E1ginas\%20Preliminares. pdf

Chorafas, Dimitris (2007).IFRS, valor razonable y gobierno corporativo. Bogotá: ECOE Ediciones.

Christensen, Hans Bonde \& Nikolaev, Valeri V. (2013). Does Fair Value Accounting for Non-Financial Assets Pass the Market Test? Review of Accounting Studies, 18, 734-775. Disponible en: http://papers.ssrn.com/sol3/ papers.cfm?abstract_id $=1269515$

Conthe, Manuel (2008). Lo irracional de lo razonable (o lo malo de las buenas noticias). Disponible en: http://www.expansion.com/ accesible/blogs/conthe/2008/03/23/27-loirracional-de-lo-razonable-o-lo.html

David, Julio César (2010).El valor razonable como criterio básico de medición. Disponible en: http://bibliotecavirtual.unl.edu.ar:8180/ tesis/bitstream/1/165/1/tesis.pdf,http:// bibliotecavirtual.unl.edu.ar:8180/publicaciones/bitstream/1/3853/1/CE_8_1_ pag_89_97.pdf 
Eguren-Galende, Tomás; Elvira-Benito, Óscar \& Larraga-Benito, Pablo (2009). Asesoramiento financiero en la práctica. Barcelona: Bresca Editorial.

Estupiñán-Gaitán, Rodrigo \& Estupiñán-Gaitán, Orlando (2008). Análisis financiero y de gestión. Colombia: ECOE Ediciones.

Fundación IFRS (2012). Illustrative examples to accompany IFRS 13 Fair Value Measurement, Unquoted equity instruments within the scope of IFRS 9 Financial Instruments. Disponible en: http://www.ifrs.org/use-around-theworld/education/fvm/documents/educationfairvaluemeasurement.pdf

García-Benau, María Antonia \& Zorio-Grima, Ana (2002). El camino hacia el valor razonable. Revista de Contabilidad, 5 (9), 57-88. Disponible en: http://www.rc-sar.es/verPdf. php?articleId $=78$

González-Losantos, Sara(2012). ¿El fin de la era del "fair value accounting"? Revista de la Asociación Española de Contabilidad y Administración de Empresas, AECA, 98, 2627. Disponible en: http://www.aeca1.org/ revistaeca/revista98/98.pdf

Gonzalo-Angulo, José Antonio (2009). Contabilidad y crisis: la fiabilidad del valor razonable. Revista de Derecho del Mercado de Valores, 4, 41-80.

Hervás-Oliver, José Luis (2005). La revaloración de activos fijos. Contraste empírico de un modelo financiero de elección contable. Revista Investigaciones Europeas de Dirección y Economía de la Empresa, 11 (1), 31-51. Disponible en: http://dialnet.unirioja.es/servlet/arti culo?codigo=1172962International
Accounting Standards Board, IASB (2014). Fundamentos de las conclusiones de la NIC 40 Propiedades de Inversión. Londres, Inglaterra: International Accounting Standards Board, IASB. Traducción oficial del Comité de Revisión de la Fundación IFRS.

International Accounting Standards Board, IASB (2014).Marco conceptual para la información financiera. Traducción oficial del Comité de Revisión de la Fundación IFRS.

International Accounting Standards Board, IASB (2010). Marco conceptual para la preparación y presentación de estados financieros. Traducción oficial del Comité de Revisión de la Fundación IFRS.

International Accounting Standards Board (2014). Norma Internacional de Información Financiera 40 Propiedades de Inversión. Londres, Inglaterra: International Accounting Standards Board, IASB. Traducción oficial del Comité de Revisión de la Fundación IFRS.

International Accounting Standards Board (2014). Norma Internacional de Información Financiera 16 Propiedades, Planta y Equipo. Londres, Inglaterra: International Accounting Standards Board, IASB. Traducción oficial del Comité de Revisión de la Fundación IFRS.

International Accounting Standards Board (2014). Norma Internacional de Información Financiera 38 Activos Intangibles. Londres, Inglaterra: International Accounting Standards Board, IASB. Traducción oficial del Comité de Revisión de la Fundación IFRS. International Accounting Standards Board (2014). Norma Internacional de Información 
Financiera 8 Políticas Contables, Cambios en las Estimaciones Contables y Errores. Londres, Inglaterra: International Accounting Standards Board, IASB. Traducción oficial del Comité de Revisión de la Fundación IFRS.

International Accounting Standards Board (2014). Norma Internacional de Información Financiera 36 Deterioro del Valor de los Activos. Londres, Inglaterra: International Accounting Standards Board, IASB. Traducción oficial del Comité de Revisión de la Fundación IFRS.

International Accounting Standards Board (2014). Norma Internacional de Información Financiera 37 Provisiones, Pasivos Contingentes y Activos Contingentes. Londres, Inglaterra: International Accounting Standards Board, IASB. Traducción oficial del Comité de Revisión de la Fundación IFRS.

International Accounting Standards Board, IASB (2014). Norma Internacional de Información Financiera NIIF 13 Medición del Valor Razonable. Londres, Inglaterra: International Accounting Standards Board, IASB. Traducción oficial del Comité de Revisión de la Fundación IFRS. Disponible en: http://www.mef.gob.pe/contenidos/ conta_publ/con_nor_co/vigentes/niif/ NIIF_013_2014.pdf

International Accounting Standards Board, IASB (2014). Página web. Disponible en: http://www.ifrs.org/Use-around-the-world/ Pages/Analysis-of-the-IFRS-jurisdictionalprofiles.aspx

Jensen, Michael \& Meckling, William (1994). Teoría de la empresa: la gerencia; costes de agencia y estructura de la propiedad. En Louis Putterman (ed.). La naturaleza económica de la empresa, 261-286. Madrid: Alianza Editorial.

Linsmeier, Thomas (2013). A Standard Setter's Framework for Selecting between Fair Value and Historical Cost Measurement Attributes: A Basis for Discussion of "Does Fair Value Accounting for Nonfinancial Assets Pass the Market Test?". Review of Accounting Studies, 18(3), 776-782.

Marchese, Domingo (2010). La aplicación del valor razonable (fair value) en la medición de los activos biológicos de largo plazo sin mercado activo. Revista Información Financiera, Gerencia y Control, 1 (1), 13-39.

Monge, Pedro (2005). Las Normas Internacionales de Contabilidad. Revista Actualidad Contable FACES, 8 (10),35-52. Disponible en: http://www.saber.ula.ve/ dspace/bitstream/123456789/17366/1/ articulo4.pdf

Morales-Díaz, José (2010). ¿Se debería aplicar el valor razonable a todos los instrumentos financieros? Revista Española de Financiación y Contabilidad, 39 (145), 169-195. Disponible en: http://www.aeca.es/pub/refc/ prestesis/Nota_145_Morales.pdf Muñoz-Merchante, Ángel (2009). El valor razonable: cautelas y desafíos. Revista Intervención General de la Administración del Estado, IGAE, 22, 48-51. Disponible en: http:/www.igae.pap.meh.es/sitios/ igae/es-ES/ClnPublicaciones/ClnRevista/ Documents/rev22.pdf

Ortiz-Anaya, Héctor (2008). Finanzas básicas para no financieros. Bogotá: Thomson. 
Otal-Franco, Sara Helena \& Serrano-García, Ramiro (2006). Reconocimiento y valoración de los activos fijos no financieros en las normas internacionales de información financiera. Revista de Estudios Jurídicos, Económicos y Sociales Saberes, 4, 1-31. Disponible en: http://www.uax.es/publicacion/ reconocimiento-y-valoracion-de-los-activosfijos-no-financieros-en-las.pdf

Plantin, Guillaume; Sapra, Haresh \& Shin, Song Hyun(2008).Fair Value Accounting and Financial Stability. Disponible en: http:// papers.ssrn.com/sol3/papers.cfm?abstract_ id $=1275395$

RIMES (2014). Página web. Disponible en: http://www.rimes.com/thomson-reutersworldscope

Rodríguez-Pérez, Gonzalo \& Solà-Tey, Magda (2007). Implicaciones en las magnitudes contables de la valoración a coste histórico vs. valor razonable. Revista de Contabilidad y Dirección, 4, 91-110. Disponible en: http:// www.accid.org/revista/documents/rcd4_ castellano_91.pdf

Romero-López, Álvaro Javier (2007). Principios de contabilidad. México: McGraw-Hill.

Ronen, Joshua (2012). What Do FAS 157 “Fair Values" Really Measure: Value or Risk? AccountingPerspectives, 11 (3), 149-164.

Silva-Palavecinos, Berta (2011). Valor razonable: un modelo de valoración incorporado en las Normas Internacionales de Información Financiera. Revista Estudios Gerenciales, 27 (118), 97-114. Disponible en: http://www.icesi.edu.co/revistas/index.php/ estudios_gerenciales/article/view/393
Silva-Palavecinos, Berta \& Azua-Álvarez, Digna (2006). Alcances sobre el concepto de valor razonable. CAPIC Review, 4, 61-75. Disponible en http://www.capic.cl/capic/media/ ART5SilvaAzua.pdf

Valle-Larrea, Carlos (2009). Contabilidad financiera: hacia el reino de la subjetividad: una crítica al modelo contable del valor razonable. Revista Legis de Contabilidad y Auditoría, 39, 133-153.

Vicente, Marta de; Molina, Horacio \& Ramírez, Jesús (2009).Los efectos procíclicos derivados de la valoración de las inversiones inmobiliarias según el modelo de valor razonable en las Normas Internacionales de Contabilidad. Conferencia dictada en el XV Congreso de la Asociación Española de Contabilidad y Administración de Empresas, realizado en España. Revista de la Asociación Española de Contabilidad y Administración de Empresas, AECA, ejemplar dedicado a XV Congreso AECA: Decidir en época de crisis: transparencia y responsabilidad, Extra 87, 72-75. Disponible en: http://www. aeca.es/faif/articulos/hmolina.pdf, http:// www.aeca1.org/revistaeca/revista87/87.pdf Vicente, Marta de; Molina, Horacio \& Ramírez, Jesús (2012). La eliminación de las alternativas contables. El caso de las inversiones inmobiliarias en la NIIF de PYMES y en la propuesta del FASB sobre entidades de inversión inmobiliaria. Revista de la Asociación Española de Contabilidad y Administración de Empresas, AECA, ejemplar dedicado a XVI Encuentro AECA: Nuevos caminos para Europa: el papel de las empresas y los 
MEDICIÓN DE ACTIVOS NO FINANCIEROS / H. CASTELLANOS / 71

gobiernos, 99, 20-22. Disponible en: http:// www.aeca.es/faif/articulos/hm_rev99.pdf Vicente, Marta de; Molina, Horacio \& Ramírez, Jesús (2013). Inversiones inmobiliarias: la elección contable valor razonable versus coste en los grupos cotizados españoles. Cuadernos de Contabilidad, 14 (34), 25-51. Disponible en: http://revistas.javeriana.edu. co/index.php/cuacont/article/view/6066

\begin{tabular}{|l|}
\hline Para citar este artículo \\
Castellanos-Sánchez, Heiberg Andrés (2015). \\
Medición de activos no financieros. Un \\
análisis de los elementos que intervienen \\
en la decisión de la gerencia al optar por el \\
modelo del valor razonable. Cuadernos de \\
Contabilidad, 16 (40), 41-71. http://dx.doi. \\
org/10.11144/Javeriana.cc16-40.manf \\
\hline
\end{tabular}

- Fecha de recepción: 19 de agosto de 2014

- Fecha de aceptación: 16 de marzo de 2015

- Disponible en línea: 30 de abril de 2015 
